\title{
PERPUSTAKAAN PERGURUAN TINGGI SEBAGAI PRIME MOVER PENINGKATAN KOMPETENSI LITERASI INFORMASI MAHASISWA
}

\author{
Budi Handari \\ Perpustakaan dan Arsip Daerah Banjarnegara, Jawa Tengah, Indonesia \\ budihandari@gmail.com
}

\begin{abstract}
Increased competence of information literacy is not only to assist students in completing their academic tasks, but also to equip them with a deep understanding of information literacy for the interests of their career ladder and the interests of the nation. The successful improvement of these competencies is a shared responsibility of libraries, students and institutions of higher education. The mission, functions and tasks carried by the college library, positioned the institution as prime mover of increasing student literacy competence. Various limitations exist, do not reduce the level of demands to the agency to perform its function as prime movers optimally.By using rational approach and deductive method, this paper examines the implementation of college library function as prime mover of increasing student literacy competence.
\end{abstract}

Keywords: competence of information literacy, prime mover

\begin{abstract}
Abstrak
Peningkatan kompetensi literasi informasi tidak hanya untuk membantu mahasiswa dalam menyelesaikan tugas-tugas akademis mereka, melainkan juga untuk membekali mereka dengan pemahaman literasi informasi yang mendalam untuk kepentingan jenjang kariernya dan kepentingan bangsa. Keberhasilan peningkatan kompetensi tersebut merupakan tanggungjawab bersama dari perpustakaan, mahasiswa dan institusi penyelenggara pendidikan tinggi. Misi, fungsi dan tugas yang diemban oleh perpustakaan perguruan tinggi,
\end{abstract}


memosisikan institusi tersebut sebagai prime mover peningkatan kompetensi literasi mahasiswa. Berbagai keterbatasan yang ada, tidak mengurangi kadar tuntutan kepada lembaga tersebut untuk melaksanakan fungsinya sebagai prime mover secara optimal. Dengan menggunakan pendekatan rasional dan metode deduktif, tulisan ini mengkaji pelaksanaan fungsi perpustakaan perguruan tinggi sebagai prime mover peningkatan kompetensi literasi mahasiswa.

Kata Kunci: kompetensi literasi informasi, prime mover

\section{A. Pendahuluan}

\section{Latar Belakang}

Pendidikan tinggi sebagai bagian dari sistem pendidikan nasional berkewajiban untuk mendukung optimalisasi pencapaian tujuan pembangunan nasional, di antaranya peningkatan daya saing bangsa. Bagi Indonesia peningkatan daya saing bangsa merupakan kebutuhan yang cukup mendesak. Menurut The Global Competitiveness Index 2015 - 2016 ${ }^{1}$, dari 140 negara, Indonesia berada di peringkat 37 di bawah Singapura (2), Malaysia (18) dan Thailand (32). Indeks Global Competitiveness dengan basic requirements Higher Education and Training ${ }^{2}$, menunjukkan Indonesia ada di urutan 65, di bawah Singapura, Malaysia, Thailand dan Filipina.

Perguruan tinggi sebagai unsur penyelenggara pendidikan tinggi memiliki peran strategis dalam upaya peningkatan daya saing bangsa. Dalam konteks tersebut perguruan tinggi dituntut untuk mampu menghasilkan intelektual, ilmuwan, dan/atau profesional yang kreatif dan berkarakter tangguh serta mampu menghadapi tantangan sesuai dengan tuntutan perubahan kehidupan lokal, nasional maupun global, sebagai dampak dari pesatnya perkembangan teknologi informasi.

${ }^{1}$ K. Schwab, X. Sala-i-Martin, and B. Brende, "The Global Competitiveness Report 2015-2016 (Vol. 5)," Google Scholar, 2015, 15.

${ }^{2}$ Schwab, Sala-i-Martin, and Brende, 29. 
Perkembangan teknologi informasi memunculkan peradaban baru, yakni berkembangnya informasi sebagai kebutuhan utama dan bagian yang tidak terpisahkan dari keseharian manusia. Revolusi teknologi informasi mengakibatkan terjadinya perubahan yang cepat, transformasi yang dinamis dan berkesinambungan ${ }^{3}$. Kondisi tersebut memengaruhi semua aspek kehidupan, termasuk pendidikan. Dalam buku The Third Wave, Alvin Toffler ${ }^{4}$ mengatakan bahwa for Third Wave civilization, the most basic raw material of all--and on that can never be exhausted-is information... With information becoming more important than ever before, the new civilization will restructure education (untuk peradaban Gelombang Ketiga, bahan baku paling dasar - dan itu tidak akan pernah habis - adalah informasi ... Dengan informasi menjadi lebih penting daripada sebelumnya, peradaban baru akan merestrukturisasi pendidikan). Pendapat senada disampaikan oleh Sirje Virkus and Silvi Metsar ${ }^{5}$, bahwa universities all over the world face an imperative to adapt and adjust to a whole series of profound changes (universitas-universitas di seluruh dunia menghadapi keharusan untuk beradaptasi dan menyesuaikan diri dengan serangkaian perubahan mendalam). Proses adaptasi dapat dilakukan antara lain dengan penyesuaian dan pembaharuan sistem serta proses belajar mengajar secara kontinyu dan konsisten. Langkah yang dilakukan dalam proses tersebut juga untuk mengantisipasi dampak lain dari kepesatan perkembangan teknologi informasi, yakni dunia "tanpa batas" (borderless). Hilangnya batas tersebut menjadikan informasi mudah untuk menyebar dan membanjiri bagian dunia manapun, melintasi batas geografis serta sosial-budaya. Untuk itu peningkatan kompetensi literasi mahasiswa menjadi wajib hukumnya. Sebagai referensi tentang pentingnya penguasaan literasi informasi, dapat disimak penyataan dari UNESCO, bahwa "freedom, prosperity and the development of society and individuals are fundamental human values. They will only be attained through the ability of well-informed citizens". (kebebasan, kemakmuran dan pengembangan masyarakat serta individu

${ }^{3}$ Sirje Virkus and Silvi Metsar, "General Introduction to the Role of the Library for University Education,” 2004, 290, https://www.liberquarterly.eu.

${ }^{4}$ Qadar Bakhsh Baloch and Nasir Kareem, "Book Review: The Third Wave," Journal of Managerial Sciences; 137 I 2 (2007): 133.

${ }^{5}$ Virkus and Silvi Metsar, "General Introduction to the Role of the Library for University Education," 291. 
adalah nilai-nilai dasar manusia. Semua itu hanya dapat dicapai melalui kemampuan warga negara untuk mengakses informasi dengan baik). Arti penting peningkatan kompetensi literasi informasi mahasiswa juga disampaikan oleh María Pinto and Rosaura Fernández-Pascual ${ }^{6}$. Dikatakan bahwa in the field of Higher Education, most experts agree that information literate competence play an important role in the overall education of students, both in their learning process and in subsequent practice. (di bidang Pendidikan Tinggi, sebagian besar ahli sepakat bahwa kompetensi literasi informasi memainkan peran penting dalam keseluruhan pendidikan mahasiswa, baik dalam proses pembelajaran mereka maupun dalam praktik).

Peningkatan kompetensi literasi mahasiswa semakin diperlukan manakala dikaitkan dengan berbagai fakta ataupun data yang ada. Penelitian Afifah ${ }^{7}$ tentang kemampuan literasi informasi mahasiswa Program Studi Pendidikan Agama Islam Fakultas Tarbiyah dan Keguruan Universitas Islam Negeri Sultan Ampel Surabaya Angkatan 2011 dalam penyusunan tugas akhir skripsi, antara lain menyimpulkan bahwa kemampuan literasi mahasiswa kurang. Mahasiswa belum memiliki tujuh keterampilan literasi informasi secara lengkap yang meliputi: merumuskan masalah, mengidentifikasi informasi, mengakses informasi, menggunakan informasi, mencintakan karya, mengevaluasi tujuan dan menarik pelajaran. Penelitian lain yang dilakukan oleh Yusuf Dzul Ikram Al Hamidy dan Heriyanto ${ }^{8}$ tentang kemampuan literasi informasi mahasiswa pada layanan American Corner di UPT Perpustakaan IAIN Walisongo Semarang pada bulan AprilJuli 2012, antara lain menyimpulkan bahwa rata-rata mahasiswa untuk menentukan jenis dan batas informasi kurang baik.

\footnotetext{
${ }^{6}$ Maria Pinto and Rosaura Fernandez-Pascual, "Information Literacy Competencies among Social Sciences Undergraduates: A Case Study Structural Equation Model," 2014, 371, link.springer.com.

${ }^{7}$ Afifah, "Kemampuan Literasi Informasi Mahasiswa Dalam Menyelesaikan Tugas Penyusunan Skripsi (Studi Kasus Di Program Studi Pendidikan Agama Islam Fakultas Tarbiyah Dan Keguruan Universitas Islam Negeri Sultan Ampel Surabaya Angkatan 2011)" (UIN Sunan Ampel Surabaya, 2015), 1, digilib.uinsby.ac.id/6761.

${ }^{8}$ Yusuf Dzul Ikram Al Hamidy and Heryanto, "Kemampuan Literasi Informasi Mahasiswa Pada Layanan American Corner Di UPT Perpustakaan IAIN Walisongo Semarang Menurut Association of College and Research Libraries," 2012, 1, portalgaruda.org.
} 
Bukan hal yang mudah untuk meningkatkan kompetensi literasi informasi mahasiswa. Johnston dan Webber ${ }^{9}$ mengatakan bahwa even in the United States, whilst much attention has been paid to information literacy by American policy-makers, librarians and academics, the results are still relatively not satisfactory yet (bahkan di Amerika Serikat, meskipun banyak perhatian telah diberikan pada literasi informasi oleh pembuat kebijakan, pustakawan dan akademisi Amerika, hasilnya masih relatif belum memuaskan). Salah satu alternatif untuk meningkatkan kompetensi literasi mahasiswa adalah dengan mendayagunakan perpustakaan perguruan tinggi secara optimal.

Keberadaan perpustakaan perguruan tinggi antara lain untuk mengumpulkan, mengolah, menyimpan, menyajikan dan menyebarluaskan informasi untuk mahasiswa dan dosen sesuai dengan kurikulum yang berlaku. Berdasarkan Surat Keputusan Menteri Pendidikan dan Kebudayaan No. 0103/O/1981, Perpustakaan Perguruan Tinggi berfungsi sebagai pusat kegiatan belajar mengajar, pusat penelitian dan pusat informasi bagi pelaksanaan tri dharma perguruan tinggi. Dalam melaksanakan fungsi tersebut, perpustakaan perguruan tinggi menempatkan diri sebagai: ${ }^{10}$

a. Studying Center, perpustakaan merupakan pusat belajar yang digunakan sebagai tempat untuk mendapatkan informasi sesuai dengan kebutuhan dalam jenjang pendidikan;

b. Learning Center, perpustakaan merupakan pusat pembelajaran dan keberadaannya berfungsi sebagai tempat untuk mendukung proses belajar mengajar;

c. Information Resources Center, perpustakaan sebagai pusat sumber informasi yang menyediakan segala macam dan jenis informasi yang dibutuhkan dalam proses belajar mengajar.

Di sisi lain berdasarkan Standar Nasional Indonesia nomor 7330: 2009, salah satu misi perpustakaan perguruan tinggi adalah meningkatkan literasi informasi pengguna. Misi, fungsi dan tugas tersebut, memosisikan perpustakaan perguruan tinggi sebagai prime mover (pendorong utama)

${ }^{9}$ Virkus and Silvi Metsar, "General Introduction to the Role of the Library for University Education,” 300.

10 Kurniawati, Rita, "Perpustakaan Perguruan Tinggi," Sharing Education Berkarya Dan Berkarya Untuk Negeri (blog), 2014, 3, https://rithateknodik.wordpress.com. 
peningkatan kompetensi literasi mahasiswa. Dengan berbagai keterbatasan yang ada, perpustakaan perguruan tinggi dituntut untuk melaksanakan fungsi tersebut dengan optimal, dan itu merupakan cakupan yang dibahas dalam kajian ini.

\section{Pendekatan Penulisan}

Kajian ini menggunakan pendekatan rasional dengan metode penalaran deduktif. Pendekatan rasional berupaya merumuskan kebenaran berdasarkan kajian data yang diperoleh dari berbagai rujukan (literatur) ${ }^{11}$. Adapun penalaran deduksi menurut Trochim ${ }^{12}$ begins with the general and ends with the specific... based on laws, rules, or other widely accepted principles (dimulai dari umum dan diakhiri dengan spesifik ... berdasarkan kepada undang-undang, peraturan, atau prinsip lain yang diterima secara luas). Pendapat lain menyatakan bahwa penalaran deduksi merupakan penggunaan logika untuk menarik satu atau lebih kesimpulan (conclusion) berdasarkan seperangkat premis yang diberikan. Metode ini sering digambarkan sebagai proses penalaran dan pengambilan kesimpulan yang bermula dari keadaan umum ke keadaan khusus ${ }^{13}$

. Dengan demikian pendekatan deduksi merupakan proses penalaran dari satu atau lebih pernyataan umum (premis) untuk mencapai kesimpulan logis tertentu.

Pembahasan dan analisis pokok-pokok bahasan dalam kajian ini mendasarkan kepada teori ataupun data yang diperoleh melalui studi kepustakaan. Dengan penelusuran literatur dapat digali teori-teori yang telah berkembang, orientasi yang lebih luas dalam permasalahan yang dikaji dan menghindari terjadinya duplikasi yang tidak diharapkan ${ }^{14}$.

11 Astuti, Rini, “Menulis Karya Ilmiah," Staffsite (blog), n.d., 9, http://riniastuti.staff.gunadarma.ac.id.

${ }^{12}$ L. Karen Soiferman, "Compare and Contrast Inductive and Deductive Research Approaches.," Online Submission, 2010, 3.

${ }^{13}$ Niyamabrata, “Jenis-Jenis Metode Pendekatan Karya Tulis," Life Is About Choice (blog), 2013, 2, ttps://konsen.wordpress.com.

${ }^{14}$ Moh. Nazir, Metode Penelitian (Jakarta: Ghalia Indonesia, 1999), 111. 


\section{Permasalahan}

Secara sederhana masalah dapat dimaknai sebagai kesenjangan antara sesuatu yang diharapkan (das sollen) dengan suatu kenyataan (das sein). Menurut Moh Nazir ${ }^{15}$, masalah timbul di antaranya karena adanya celah (gap) baik antar kegiatan atau antar fenomena, yang telah ada ataupun yang akan ada. Masalah pada hakikatnya tidak pernah berdiri sendiri atau terisolasi dari faktor-faktor lainnya. Karena itu masalah selalu berkonstelasi dengan faktor lainnya, sehingga menjadi latar belakang suatu masalah tertentu ${ }^{16}$.

Berdasarkan fakta dan fenomena sebagaimana diuraikan pada latar belakang masalah, maka rumusan masalah yang menjadi fokus kajian ini adalah apa yang harus dilakukan agar perpustakaan perguruan tinggi dapat melaksanakan fungsinya sebagai prime mover (pendorong utama) peningkatan kompetensi literasi informasi mahasiswa dengan baik.

\section{B. Pembahasan}

\section{Literasi Informasi}

Literasi informasi merupakan terjemahan dari kata information literacy. Terjemahan lain dari istilah tersebut adalah melek informasi atau keberaksaraan informasi. Sejatinya istilah literasi informasi sudah cukup lama diperkenalkan di Amerika Serikat, sekitar dasawarsa 1970an oleh Paul Zurkowski. Menurut pendapatnya, orang yang literat informasi adalah orangorang yang terlatih dalam aplikasi sumberdaya dalam pekerjaannya ${ }^{17}$. Walaupun konsep literasi informasi sudah lama diketahui, namun belum ada kesepakatan di antara para ahli tentang pengertian istilah tersebut. Dikatakan oleh Snavely dan Cooper $^{18}$, bahwa untuk dapat diterima oleh pemakai non

\footnotetext{
${ }^{15}$ Nazir, 333.
}

${ }^{16}$ Husaini Usman and Purnomo Setiady Akbar, Metodologi penelitian sosial (Jakarta: Bumi Aksara, 2004), 16.

17 Sulistyo-Basuki, "Literasi Informasi Dan Literasi Digital,” 2013, 1, https://sulistyobasuki.wordpress.com.

${ }^{18}$ Sulistyo-Basuki, 1. 
pustakawan dan akademisi, perlu dijelaskan definisi literasi informasi serta perbedaannya dengan pendidikan dan pembelajaran pada umumnya. Menurut Owusu-Ansah ${ }^{19}$ banyaknya definisi dan konsep menunjukkan adanya perbedaan atau ketidaksepakatan yang besar tentang pengertian literasi informasi.

American Library Association mendefinisikan literasi informasi sebagai the ability to recognize when information is needed and have the ability to locate, evaluate, and use effectively the needed information (kemampuan untuk "mengenali kapan informasi dibutuhkan dan memiliki kemampuan untuk menemukan, mengevaluasi, dan menggunakan secara efektif informasi yang dibutuhkan $)^{20}$. Menurut Chatered Institute of Library and Information Professional (CILIP) ${ }^{21}$ literasi informasi adalah mengetahui kapan dan mengapa membutuhkan informasi, dimana menemukan informasi, bagaimana mengevaluasi, menggunakan dan mengomunikasikan informasi dengan cara yang tepat.

Dalam perkembangannya kesepakatan tentang definisi literasi informasi tercapai pada tahun 2005, ketika The International Federation of Library Associations and Institutions (IFLA), UNESCO dan National Forum for Information Literacy (NFIL) menyelenggarakan pertemuan tingkat tinggi di Alexandria, Mesir. Hasil dari pertemuan tersebut antara lain ditemukannya titik temu tentang pengertian literasi informasi. Disepakati bahwa information literacy encompasses knowledge of one's information concerns and needs, and the ability to identify, locate, evaluate, organize, and effectively create, use and communicate information to address issues or problems at hand (literasi informasi mencakup pengetahuan tentang masalah dan kebutuhan informasi, serta kemampuan untuk mengidentifikasi, menemukan, mengevaluasi, mengatur, menggunakan dan mengkomunikasikan informasi secara efektif' untuk mengatasi isu atau masalah yang dihadapi). ${ }^{22}$ Dari berbagai pendapat terdahulu dapat ditarik

${ }^{19}$ Sulistyo-Basuki, "Literasi Informasi Dan Literasi Digital."

${ }^{20}$ Kalarensi Naibaho, "Menciptakan Generasi Literat Melalui Perpustakaan," Visi Pustaka 9, no. 3 (2007): 5.

${ }^{21}$ Sulistyo-Basuki, "Literasi Informasi Dan Literasi Digital," 2.

${ }^{22}$ Sulistyo-Basuki, 1. 
suatu pemahaman bahwa secara sederhana literasi informasi dapat dimaknai sebagai kemampuan, keterampilan untuk mencari, menelusur, menganalisis, mengevaluasi memanfaatkan dan menggunakan informasi yang dibutuhkan secara efisien, efektif dan etis.

Literasi informasi selain memudahkan mahasiswa untuk menyelesaikan tugas-tugas akademis dengan baik, manfaat lainnya adalah ${ }^{23}$ :

a. Membekali mahasiswa dengan ketrampilan untuk pembelajaran seumur hidup. (lifelong learning);

b. Membantu mahasiswa untuk memanfaatkan informasi yang relevan sebagai sarana decision making (pengambilan keputusan);

c. Memungkinkan mahasiswa untuk mengkritisi daya guna informasi;

d. Mendorong mahasiswa untuk berpikir kritis dan kreatif (critical \& creative thinking).

Beberapa model yang dapat digunakan untuk mengidentifikasi berbagai komponen dan menunjukkan hubungan antar komponen, serta menjelaskan apa yang dimaksud dengan literasi informasi, antara lain: ${ }^{24}$

a. The Big 6

Model ini dikembangkan di Amerika Serikat oleh dua pustakawan, Mike Eisdenberg dan Bob Berkowitz. The Big 6 menggunakan pendekatan pemecahan masalah untuk mengajar informasi dan ketrampilan informasi serta teknologi.

b. The Seven Pillars of Information Literacy

SCONUL (Standing Conference of National and University Libraries) di Inggris mengembangkan model konseptual yang disebut Seven Pillars of Information Literacy. Model 7 Pilar terdiri dari 2 himpunan ketrampilan, yakni bagaimana menentukan lokasi informasi dan mengaksesnya, serta bagaimana memahami dan menggunakan informasi.

c. Empowering Eight (E8)

Empowering Eight (E8) menggunakan pendekatan pemecahan masalah untuk resource-based learning.

${ }^{23}$ Imam Budi Prasetiawan, "Keberaksaraan Informasi (Information Literacy) Bagi SDM Pengelola Perpustakaan Di Era Keterbukaan Informasi," 2014, 2, www.slis.tsukuba.ac.jp.

${ }^{24}$ Sulistyo-Basuki, "Literasi Informasi Dan Literasi Digital,” 1-10. 
d. Bruce's Seven Faces of Information Literacy

Model ini menggunakan pendekatan informasi terhadap literasi informasi.

Memahami berbagai jenis literasi informasi diperlukan oleh mahasiswa. Selain untuk menghindari terjadinya "gagal paham", pemahaman tersebut juga membantu mahasiswa dalam memanfaatkan informasi secara akurat. Keberaksaraan informasi terdiri dari berbagai literasi ${ }^{25}$, yakni:

a. Literasi Visual, yakni kemampuan untuk memahami dan menggunakan citra, termasuk kemampuan untuk berpikir, belajar, dan mengungkapkan diri sendiri dalam konteks citra;

b. Literasi Media, yaitu kemampuan seseorang untuk menggunakan berbagai media guna mengakses, menganalisis dan menghasilkan informasi untuk berbagai keperluan;

c. Literasi Teknologi Komputer dan Komunikasi, adalah kemampuan untuk mengetahui bagaimana menggunakan dan mengoperasikan komputer secara efisien sebagai mesin pemroses informasi;

d. Literasi Jaringan, merupakan literasi untuk menggunakan jaringan digital secara efektif, dan berkembang pesat karena keberadaan internet;

e. Literasi Kultural, yakni pengetahuan dan pemahaman tentang bagaimana tradisi, kepercayaan, simbol serta ikon, sarana dan prasarana komunikasi sebuah negara, agama, kelompok etnik atau suku;

f. Literasi Digital, merupakan kemampuan untuk berhubungan dengan informasi hipertekstual berbantuan komputer.

Menurut Rosanne Marie Cordell ${ }^{26}$, secara intuitif dapat diketahui adanya hubungan yang erat antara literasi informasi dan literasi digital, walaupun mereka tidaklah sama. Dikatakan bahwa "literasi informasi dan literasi digital bukanlah konsep yang saling bersaing, melainkan saling melengkapi. Konsep literasi digital memberikan dasar-dasar pengelolaan

${ }^{25}$ Sulistyo-Basuki, 10-13.

${ }^{26}$ Rosane Mary Cordel, "Information Literacy and Digital Literacy Competing or Complementary?, Northern Illinois University Communications in Information Literacy" Vol.7, no. 2 (2013): 2, files.eric.ed.gov. 
lingkungan digital yang dibutuhkan untuk keberhasilan penguasaan dalam literasi informasi".

\section{Kompetensi Literasi Informasi Mahasiswa}

Istilah kompetensi pertama kali dipopulerkan oleh Boyatzis ${ }^{27}$. Dia mendefinisikan kompetensi sebagai kemampuan yang dimiliki oleh seseorang yang nampak pada sikapnya, sesuai dengan kebutuhan kerja dalam parameter lingkungan organisasi dan memberikan hasil yang diinginkan. Menurut Rotwell ${ }^{28}$, kompetensi adalah an area of knowledge or skill that is critical for production of outputs...capabilities which may be expressed in a broad, even infinite array of on the job behaviour (area pengetahuan atau keterampilan yang penting untuk produksi keluaran...kemampuan yang dapat diekspresikan dalam penampilan perilaku yang luas dan bahkan tak terbatas). Dari ke dua pengertian tersebut dapat disimak adanya tiga elemen penting dari kompetensi, yakni pengetahuan, keterampilan dan perilaku. Pendapat lain mengatakan bahwa a competency is the capability to apply or use a set of related knowledge, skills, and abilities required to successfully perform "critical work functions" or tasks.... Competence indicates sufficiency of knowledge and skills that enable someone to act in a wide variety of situations (kompetensi adalah kemampuan untuk menerapkan atau menggunakan seperangkat pengetahuan, keterampilan, dan kemampuan terkait yang diperlukan agar berhasil melakukan "fungsi kerja kritis" atau tugas......Kompetensi menunjukkan kecukupan pengetahuan dan keterampilan yang memungkinkan seseorang untuk bertindak dalam berbagai situasi). ${ }^{29}$

Berkaitan dengan keberaksaraan informasi, ada pendapat yang mengatakan bahwa kompetensi literasi informasi adalah a set of abilities requiring individuals to recognize when information is needed and have the ability to locate, evaluate, and use effectively the needed information (seperangkat kemampuan yang mengharuskan individu untuk mengenali

${ }^{27}$ Lembaga Administrasi Negara, "Sistem Administrasi Negara Kesatuan Republik Indonesia,” 2003, 75, http://www/lan.go.id.

${ }^{28}$ Lembaga Administrasi Negara, "Sistem Administrasi Negara Kesatuan Republik Indonesia," 2003, 75, http://www/lan.go.id.

${ }^{29}$ Dada Adefolami, "What Is Competency," 2016, 1, thenewsnigeria.com.ng. 
kapan informasi dibutuhkan dan memiliki kemampuan untuk menemukan, mengevaluasi, dan menggunakan secara efektif informasi yang dibutuhkan) ${ }^{30}$. Dengan demikian secara sederhana kompetensi literasi informasi mahasiswa dapat diartikan sebagai seperangkat sikap, pengetahuan, dan keterampilan yang harus dimiliki, dihayati, dan dikuasai oleh mahasiswa untuk mengenali kapan informasi dibutuhkan serta memiliki kemampuan untuk menemukan, mengevaluasi informasi tersebut, dan menggunakannya secara efektif dan etis.

Bagi institusi pendidikan tinggi yang sudah menerapkan kurikulum berbasis kompetensi, penguasaan literasi informasi perlu dimiliki oleh setiap mahasiswa. Menurut California State University manfaat kompetensi literasi informasi bagi mahasiswa antara lain: ${ }^{31}$

a. Providing an approved method that can guide students to various developing sources of information (Menyediakan metode yang disetujui yang dapat membimbing mahasiswa ke berbagai sumber informasi yang berkembang);

b. Supporting the nation's attempt to increase the quality of education. Providing extra facilities and tools to strengthen university studies (Mendukung upaya bangsa untuk meningkatkan kualitas pendidikan. Menyediakan fasilitas dan alat tambahan untuk memperkuat studi universitas);

c. Increasing the life learning lesson (Meningkatkan pembelajaran hidup).

Kompetensi literasi informasi membantu mahasiswa dalam menyelesaikan studi dan menyiapkan jenjang karier dalam kehidupannya. Dalam konteks tersebut, lima kompetensi dasar yang wajib dikembangkan oleh mahasiswa adalah: ${ }^{32}$

a. Sadar akan kebutuhan informasi

Memiliki kesadaran akan nilai informasi sebagai masukan untuk

30 “Information Competency Defined,” 2016, 1, Information Competency Defined.

${ }^{31}$ Indira Irawati, "Information Literacy Competency of Library and Information Science Students at the Faculty of Humanities University of Indonesia," 2014, 483, www.slis.tsukuba.ac.jp.

32 Prasetiawan, "Keberaksaraan Informasi (Information Literacy) Bagi SDM Pengelola Perpustakaan Di Era Keterbukaan Informasi," 3-4. 
mengatasi anomali dalam dirinya (misalnya untuk membuat suatu keputusan);

b. Tahu bagaimana cara mengakses informasi

Kompetensi ini menuntut adanya pengetahuan perihal sumber informasi (tercetak maupun elektronik dengan berbagai varian formatnya) serta tahu cara atau metode yang efektif dan efisien untuk menelusur informasi yang dibutuhkan (seperti menggunakan daftar isi, indeks, katalog, maupun formula kata kunci di search engine);

c. Tahu dan mengerti bagaimana mengevaluasi informasi yang diperoleh

Kompetensi ini menuntut wawasan pribadi dalam memahami dan menimbang aspek-aspek ideologi, sosio-kultural, maupun politis dari informasi yang telah diperoleh. Kompetensi ini berfungsi sebagai filter pribadi yang kemudian menentukan informasi yang relevan dengan kebutuhan dan cocok dengan preferensi ataupun prinsip pribadi pencari informasi;

d. Mampu mengelola informasi yang diperoleh

Pencari informasi mampu mengorganisasi hasil pemilahan atas temuan informasinya. Mengorganisasi berarti bagaimana seseorang mengklasifikasi informasi pilihannya menjadi suatu tatanan kumpulan informasi untuk disimpan (baik dalam bentuk cetak maupun elektronik), sehingga memudahkan yang bersangkutan untuk memanfaatkanya.

e. Mampu memanfaatkan informasi sesuai dengan etika maupun hukum yang berlaku

Kemampuan memanfaatkan informasi sesuai dengan rambu-rambu etika akademis (persoalan sitasi) maupun peraturan mengenai hak kekayaan intelektual, sehingga tidak akan terjadi tindakan plagiarisme (plagiat) ataupun pelanggaran Hak Cipta.

Untuk mengetahui tingkat kompetensi literasi informasi mahasiswa, Association of College \& Reserarch Libraries (ACRL) ALA ${ }^{33}$ menggunakan parameter:

a. The information literate student determines the nature and extent of

${ }^{33}$ Irawati, "Information Literacy Competency of Library and Information Science Students at the Faculty of Humanities University of Indonesia," 4384. 
the information needed. (Mahasiswa literat informasi menentukan sifat dan luasnya informasi yang dibutuhkan), dengan indikator:

1) The information literate student defines and articulates the need for information (Mahasiswa yang literat informasi melukiskan dan mengartikulasikan kebutuhan akan informasi);

2) The information literate student identifies a variety of types and formats of potential sources for information (Mahasiswa yang literat informasi mengidentifikasi berbagai jenis dan format sumber potensial untuk mendapatkan informasi);

3) The information literate student considers the costs and benefits of acquiring the needed information. (Mahasiswa yang literat informasi mempertimbangkan biaya dan manfaat untuk mendapatkan informasi yang dibutuhkan);

4) The information literate student reevaluates the nature and extent of the information need. (Mahasiswa yang literat informasi mengevaluasi sifat dan tingkat kebutuhan informasi).

b. The information literate student accesses needed information effectively and efficiently. (Mahasiswa yang literat informasi mengakses informasi yang dibutuhkan secara efektif dan efisien), dengan indikator:

1) The information literate student selects the most appropriate investigative methods or information retrieval systems for accessing the needed information. (Mahasiswa yang literat informasi memilih metode investigasi atau sistem pencarian informasi yang paling tepat untuk mengakses informasi yang dibutuhkan);

2) The information literate student constructs and implements effectively-designed search strategies. (Mahasiswa yang literat informasi melampirkan dan menerapkan strategi pencarian yang dirancang secara efektif);

3) The information literate student retrieves information online or in person using a variety of methods. (Mahasiswa yang literat informasi mengambil informasi secara online atau secara langsung dengan menggunakan berbagai metode);

4) The information literate student refines the search strategy if necessary (Mahasiswa yang literat informasi memperluas 
strategi pencarian jika diperlukan);

5) The information literate student extracts, records, and manages the information and its sources. (Mahasiswa yang literat informasi, mencatat dan mengelola informasi serta sumbernya).

c. The information literate student evaluates information and its sources critically and incorporates selected information into his or her knowledge base and value system (Mahasiswa yang literat informasi mengevaluasi informasi dan sumbernya secara kritis serta memasukkan informasi yang dipilih ke dalam basis pengetahuan dan sistem nilainya), dengan indikator:

1) The information literate student summarizes the main ideas to be extracted from the information gathered (Mahasiswa yang literat informasi melukiskan gagasan utama yang akan diambil dari informasi yang dikumpulkan);

2) The information literate student articulates and applies initial criteria for evaluating both the information and its sources (Mahasiswa yang literat informasi melukiskan dan menerapkan kriteria awal untuk mengevaluasi informasi serta sumbernya);

3) The information literate student synthesizes main ideas to construct new concepts (Mahasiswa yang literat informasi menyintesiskan gagasan utama untuk membangun konsep baru);

4) The information literate student compares new knowledge with prior knowledge to determine the value added, contradictions, or other unique characteristics of the information (Mahasiswa yang literat informasi membandingkan pengetahuan baru dengan pengetahuan sebelumnya untuk menentukan nilai tambah, kontradiksi, atau karakteristik unik dari informasi tersebut);

5) The information literate student determines whether the new knowledge has an impact on the individual's value system and takes steps to reconcile differences (Mahasiswa yang literat informasi menentukan apakah pengetahuan baru tersebut berdampak pada sistem nilai individu dan mengambil langkahlangkah untuk memadukan perbedaan);

6) The information literate student validates understanding and 
interpretation of the information through discourse with other individuals, subject-area experts, and/or practitioners (Mahasiswa yang literat informasi melegalkan pemahaman dan interpretasi informasi melalui wacana dengan individu lain, pakar di bidangnya, dan / atau praktisi);

7) The information literate student determines whether the initial query should be revised (Mahasiswa yang literat informasi menentukan apakah permintaan awal harus direvisi).

d. The information literate student, individually or as a member of a group, uses information effectively to accomplish a specific purpose (Mahasiswa yang literat informasi, secara individu atau sebagai anggota kelompok, menggunakan informasi secara efektif untuk mencapai tujuan tertentu), dengan indikator:

1) The information literate student applies new and prior information to the planning and creation of a particular product or performance (Mahasiswa yang literat informasi melampirkan informasi baru dan sebelumnya kepada perencanaan serta pembuatan produk atau kinerja tertentu);

2) The information literate student revises the development process for the product or performance (Mahasiswa yang literat informasi merevisi proses pengembangan produk atau kinerja);

3) The information literate student communicates the product or performance effectively to others (Mahasiswa yang literat informasi mengkomunikasikan produk atau kinerjanya secara efektif kepada orang lain).

e. The information literate student understands many of the economic, legal, and social issues surrounding the use of information and accesses and uses information ethically and legally (Mahasiswa yang literat informasi memahami banyak masalah ekonomi, hukum, dan sosial seputar penggunaan informasi dan akses serta penggunaan informasi secara etis dan legal), dengan indikator:

1) The information literate student understands many of the ethical, legal and socio-economic issues surrounding information and information technology (Mahasiswa yang melek informasi memahami banyak masalah etika, hukum dan 
sosio-ekonomi seputar informasi dan teknologi informasi);

2) The information literate student follows laws, regulations, institutional policies, and etiquette related to the access and use of information resources (Mahasiswa yang literat informasi mengikuti hukum, peraturan, kebijakan kelembagaan, dan etiket terkait dengan akses dan penggunaan sumber informasi);

3) The information literate student acknowledges the use of information sources in communicating the product or performance (Mahasiswa yang literat informasi mengakui penggunaan sumber informasi dalam mengkomunikasikan produk atau kinerja).

Uraian terdahulu membawa kepada suatu pemahaman bahwa kompetensi literasi informasi mahasiswa antara lain berkaitan dengan kemampuan mereka untuk mengakses dan memanfaatkan secara benar sejumlah informasi yang tersedia di internet. Karena itu mahasiswa harus memiliki pengetahuan atau keterampilan dan strategi penelusuran informasi.

Penelusuran informasi merupakan kegiatan menelusur kembali seluruh atau sebagian informasi yang pernah ditulis atau diterbitkan melalui sarana temu kembali informasi yang tersedia. Sedangkan strategi penelusuran adalah penelusuran yang dilakukan secara sistematis (systematic searching), yang meliputi cara-cara bagaimana menggunakan kata kunci (keyword), frase, subjek dokumen, menggunakan logika Boolean (Boolean logic) serta fasilitas-fasilitas penelusuran lain yang tersedia pada masingmasing search engines. Dengan strategi penelusuran mahasiswa (user), dapat menemukan dokumen atau informasi yang dibutuhkan secara cepat dan tepat/relevan ${ }^{34}$.

\section{Perpustakaan Perguruan Tinggi Sebagai Prime Mover Peningkatan Literasi Informasi Mahasiswa}

Secara filosofi prime mover yang berasal dari bahasa Latin primum movens, primus movere, merupakan a monotheistic concept advanced by Aristotle as a primary cause or "mover" of all the motion in the

${ }^{34}$ Prasetiawan, "Keberaksaraan Informasi (Information Literacy) Bagi SDM Pengelola Perpustakaan Di Era Keterbukaan Informasi," 4. 
universe (sebuah konsep monoteistik yang dikembangkan oleh Aristoteles sebagai penyebab utama atau "penggerak" semua gerak di alam semesta) ${ }^{35}$. Aristoteles berpendapat bahwa segala sesuatu di dunia ini terus berubah, behind every movement there must be a chain of events that brought about the movement that we see taking place. The chain of events lead back to something which moves but is itself unmoved. This is referred to as the Prime Mover (dibalik setiap gerakan pasti ada rangkaian peristiwa yang membawa pergerakan tersebut terjadi. Rantai peristiwa mengarah kembali ke sesuatu yang bergerak namun tetap pada tempatnya. Ini disebut sebagai Prime Mover $)^{36}$. Menurut Merriam-Webster Dictionary prime mover adalah a person or thing that starts something or that has a very powerful influence on something (seseorang atau suatu hal yang memulai sesuatu atau yang memiliki pengaruh sangat kuat terhadap sesuatu tersebut). Dengan demikian secara sederhana prime mover dapat dimaknai sebagai variabel yang memiliki pengaruh sangat kuat sehingga mampu menjadi penyebab atau pendorong utama terhadap keberadaan variabel lain. Dalam konteks kompetensi literasi informasi mahasiswa, perpustakaan berfungsi sebagai prime mover peningkatan kompetensi tersebut. Sebagai prime mover, perpustakaan perguruan tinggi:

a. Mengikuti perkembangan kurikulum serta perkuliahan dan menyediakan bahan-bahan yang dibutuhkan untuk pengajaran atau proses pembelajaran;

b. Menyediakan pustaka yang dibutuhkan untuk menyelesaikan tugastugas dalam rangka studi;

c. Mengikuti perkembangan program-program penelitia $n$ yang diselenggarakan di lingkungan Perguruan Tinggi induknya dan berusaha menyediakan literatur ilmiah serta bahan lain yang diperlukan bagi peneliti;

d. Memutakhirkan koleksi dengan mengikuti terbitan-terbitan yang baru baik berupa tercetak maupun tidak tercetak;

e. Menyediakan fasilitas yang memungkinkan pengguna mengakses perpustakaan lain maupun pangkalan-pangkalan data melalui jaringan

\footnotetext{
${ }^{35}$ Anonim, "Prime Mover," 2017, 1, https://en.wikipedia.org/wiki.

36 “Aristotle: The Prime Mover," 2015, 3, www.scandalon.co.uk.
} 
lokal (intranet) maupun global (internet) dalam rangka pemenuhan kebutuhan informasi yang diperlukan. ${ }^{37}$

Peningkatan kompetensi literasi informasi pada hakikinya adalah merupakan upaya pemberdayaan mahasiswa di bidang informasi, utamanya untuk mengakses dan memanfaatkan informasi dengan baik dan benar. Selain untuk mempermudah pelayanan, upaya tersebut sejatinya juga merupakan pemindahan/penularan kemampuan dan keterampilan dari pustakawan/tenaga perpustakaan kepada mahasiswa untuk mencari dan menemukan informasi. Hal tersebut dimaksudkan agar mahasiswa mampu mengembangkan kemampuan berpikir kritis dalam menyelesaikan masalah yang dihadapi.

Seiring dengan pesatnya perkembangan teknologi informasi, volume informasi dalam format elektronik jauh melebihi informasi dalam format tercetak. Karena itu penumbuhan budaya digital agar mahasiswa mampu dan terbiasa untuk mengakses berbagai sumber daya informasi elektronik, adalah merupakan suatu keharusan.

Pemindahan/penularan kemampuan dan keterampilan serta penumbuhan budaya digital, antara lain dapat dilakukan melalui pendidikan pengguna (user education). The American Library Association ${ }^{38}$ menyatakan bahwa user education as encompassing all types of activities designed to teach users about library services, facilities and organization, library resources, and search strategies (pendidikan pengguna mencakup semua jenis kegiatan yang dirancang untuk mengajarkan pengguna tentang layanan perpustakaan, fasilitas dan organisasi, sumber perpustakaan, dan strategi pencarian). Menguatkan pendapat tersebut, Mews ${ }^{39}$ mengatakan bahwa process of broad and continuous user education that is an integral part of student learning (proses pendidikan pengguna yang luas dan

\footnotetext{
37 Rina Kurniawati, "Perpustakaan Perguruan Tinggi," 2014, 2, rithateknodik.wordpress.com.

${ }^{38}$ K. Agyen-Gyasi, "User Education at the Kwame Nkrumah University of Science and Technology (KNUST) Library: Prospects and Challenges," 2008, 2, digitalcommons.unl.edu.

${ }^{39}$ K. Agyen-Gyasi, 2.
} 
berkesinambungan adalah merupakan bagian integral dari pembelajaran mahasiswa). Menurut Fidzani ${ }^{40}$ tujuan pendidikan pengguna adalah:

a. to introduce students to facilities and resources in the library (mengenalkan mahasiswa pada fasilitas dan sumber daya di perpustakaan);

b. to develop library skills (mengembangkan keterampilan perpustakaan);

c. to make students independent users and learners in the library (menjadikan mahasiswa sebagai pengguna independen dan peserta didik di perpustakaan);

d. to develop student capabilities as self-sufficient users (mengembangkan kemampuan mahasiswa sebagai pengguna mandiri);

e. to establish the library as the centre of academic activity(menjadikan perpustakaan sebagai pusat kegiatan akademik);

f. to provide basic understanding of the library so that users can make efficient use of library material and services (memberikan pemahaman dasar tentang perpustakaan sehingga pengguna dapat memanfaatkan bahan dan layanan perpustakaan secara efisien);

g. to educate users about information sources and resources and how to exploit such resources effectively and efficiently (mendidik pengguna tentang sumber informasi dan sumber daya serta bagaimana memanfaatkan sumber daya tersebut secara efektif dan efisien).

Dampak lain akibat perkembangan teknologi informasi adalah meningkatnya permintaan informasi digital. Pencari informasi tidak lagi puas hanya dengan materi cetak. Mereka ingin melengkapi informasi yang dicetak dengan sumber daya elektronik yang lebih dinamis. Menyikapi tuntutan tersebut, perpustakaan perguruan tinggi mendesain ulang layanan untuk memenuhi perubahan kebutuhan informasi para pengguna. Sejalan dengan itu, Roswitha Poll ${ }^{41}$ menyarankan agar libraries must redefine their role in information seeking and information retrieval (perpustakaan harus mendefinisikan kembali peran mereka dalam pencarian informasi dan

\footnotetext{
${ }^{40}$ K. Agyen-Gyasi, 1.

41 Roswitha Poll, "Impact/Outcome Measures for Libraries," 2003, 6, https://www.liberquarterly.eu.
} 
penemuan kembali informasi). Untuk itu penerapan, pembangunan dan pendayagunaan sistem digital pada perpustakaan perguruan tinggi merupakan kebutuhan yang tidak bisa ditawar lagi.

Perpustakaan dikategorikan sebagai digital library, apabila koleksinya disimpan dalam format digital (berlawanan dengan media cetak, microform, atau media lainnya) dan dapat diakses oleh komputer. Konten dapat disimpan secara lokal, atau diakses dari jarak jauh ${ }^{42}$. Pendapat senada disampaikan oleh Gary Marchionini dan Hermann Maurer ${ }^{43}$, bahwa digital libraries combine technology and information resources to allow remote access, breaking down the physical barriers between resources (perpustakaan digital menggabungkan teknologi dan sumber informasi untuk memungkinkan akses jarak jauh, memecah hambatan fisik di antara sumber daya).

Dengan menerapkan sistem digital, perpustakan antara lain dapat ${ }^{44}$ :

a. Mengakses informasi ke pengguna dimanapun mereka berada dan kapanpun mereka membutuhkannya;

b. Mengakses ke sumber informasi primer;

c. Mengakses jaringan di Intranet dan Internet;

d. Melakukan integrasi dengan perpustakaan digital lainnya.

Keberhasilan pelaksanaan fungsi perpustakaan perguruan tinggi sebagai prime mover peningkatan kompetensi literasi informasi mahasiswa juga dipengaruhi oleh intensitas interaksi antara perpustakan dan mahasiswa. Pada satu sisi perpustakaan menghendaki bahwa perpustakaan dimanfaatkan oleh mahasiswa dengan berbagai layanan dan fasilitasnya, di sisi lain mahasiswa membutuhkan informasi dan pengetahuan yang dimiliki oleh perpustakaan guna menambah pengetahuan, wawasan, pengalaman dan keterampilan mereka. Untuk mengetahui kebutuhan mahasiswa dan mengukur tingkat kepuasan mereka, dapat dilakukan melalui survei

${ }^{42}$ Mayank Trivedi, "Digital Libraries: Functionality, Usability, and Accessibility," 2003, 1, www.webpages.uidaho.edu.

${ }^{43}$ Gary Marchionini and Hermann Maurer, "The Roles of Digital Libraries in Teaching and Learning," 1995, 3, https://ils.unc.edu.

${ }^{44}$ Trivedi, "Digital Libraries: Functionality, Usability, and Accessibility,” 3. 
pengguna. Menguatkan premis tersebut, Chamani Gunasekera ${ }^{45}$ mengatakan bahwa since the university library is committed to provide an excellent service for its users, it has to develop an on-going dialog with the users. One of the main tools that can be used to assess the library services is the user surveys (semenjak perpustakaan universitas berkomitmen untuk memberikan layanan terbaik bagi penggunanya, maka perpustakaan tersebut harus mengembangkan dialog dengan para pengguna Salah satu alat utama yang bisa digunakan untuk menilai layanan perpustakaan adalah survei pengguna).

Dari uraian terdahulu, maka untuk menunjang keberhasilan pelaksanaan fungsi perpustakaan perguruan tinggi sebagai prime mover peningkatan kompetensi literasi mahasiswa diperlukan dukungan langkahlangkah yang sinergis dan komprehensif. Langkah-langkah tersebut, antara lain:

a. Optimalisasi pelaksanaan fungsi perpustakaan: ${ }^{46}$

1) Fungsi Informasi. Sebagai pusat informasi perpustakaan perguruan tinggi harus dapat menyajikan informasi yang dibutuhkan oleh pengguna.

2) Fungsi Pendidikan. Sebagai pusat belajar dan penelitian perpustakaan perguruan tinggi harus menyediakan materimateri pembelajaran yang berkualitas;

3) Fungsi Rekreasi. Perpustakaan perguruan tinggi harus menyediakan tata ruang dan koleksi yang membuat pemustaka merasa nyaman dan puas.

b. Penyelenggaraan pelayanan prima yang memenuhi kaidah-kaidah:

1) Transparansi. Perpustakaan perguruan tinggi harus dapat menunjukkan keterbukaan dan menjamin akses para pemangku kepentingan terhadap berbagai informasi tentang kebijakan pelayanan publik yang dilakukan ${ }^{47}$;

${ }^{45}$ Chamani Gunasekera, "Students Usage of an Academic Library: A User Survey Conducted at the Main Library University of Peradeniya" Vol. 14, no. 1 (2010): 43, jula.sljol.info/article.

${ }^{46}$ Sulistyo-Basuki, Pengantar Ilmu Perpustakaan (Jakarta: Gramedia, 1991), 36. 2005), 229.

${ }^{47}$ Agus Dwiyanto, Transparansi Pelayanan Publik (Gadjah Mada University Press, 
2) Responsivitas. Perpustakaan perguruan tinggi harus mampu mengenali kebutuhan pengguna, dan mengembangkan program-program pelayanan sesuai dengan kebutuhan dan aspirasi mereka ${ }^{48}$

3) Responsibilitas. Perpustakaan perguruan tinggi harus mampu menunjukkan kesesuaian dan konsistensi pelaksanaan pelayanan dengan prinsip-prinsip administrasi pelayanan publik yang telah ditetapkan, seperti misalnya Standar Pelayanan Minimal, Standar Operating Prosedur, dll. ${ }^{49}$

4) Akuntabilitas. Perpustakaan perguruan tinggi dapat mempertanggungjawabkan pelaksanaan kegiatan layanan sesuai dengan norma yang berlaku ${ }^{50}$.

c. Peningkatan kualitas sumberdaya manusia, infrastruktur dan pembangunan serta pendayagunaan perpustakaan digital. Byrne ${ }^{51}$ mengatakan bahwa tanpa infrastruktur yang baik, sulit bagi perpustakaan untuk menyediakan dan memberikan layanan yang dapat memenuhi kebutuhan masyarakat. Demikian pula dengan kompetensi para penyelenggara perpustakaan perguruan tinggi, pustakawan dan tenaga teknis perpustakaan dituntut untuk memiliki skill, knowledge dan attitude yang memadai.

Pelaksanaan fungsi prime mover menghadapi hambatan akibat kelemahan dan keterbatasan yang ada pada perpustakaan perguruan tinggi. Kelemahan dan keterbatasan tersebut antara lain berkaitan dengan ketersediaan koleksi bahan pustaka, sarana dan prasarana, sumberdaya manusia serta pendanaan. Untuk mengatasi hambatan tersebut, perpustakaan dapat melakukan:

a. Kerjasama Perpustakaan Perguruan Tinggi, antara lain dalam bentuk: kerjasama pengadaan; kerjasama pemusatan pengadaan dan penyimpanan; kerjasama pertukaran dan redistribusi; kerjasama

${ }^{48}$ Agus Dwiyanto, Reformasi Birokrasi Publik Di Indonesia (Yogyakarta: Pusat Studi Kependudukan dan Kebijakan Universitas Gadjah Mada, 2002), 48.

${ }^{49}$ Dwiyanto, 49.

${ }^{50}$ Dwiyanto, 49.

${ }^{51}$ Alex Byrne, 2013, 4, alex.byrne@uts.edu.au. 
pengolahan; kerjasama penyediaan fasilitas; kerjasama pinjam antar perpustakaan; kerjasama antar pustakawan; kerjasama penyusunan katalog induk; kerjasama pemberian jasa informasi.

b. "Advokasi" dengan pembuat kebijakan. Langkah ini merupakan tindakan mempengaruhi sesuatu atau seseorang yang berkaitan dengan kebijakan publik ${ }^{52}$. Kegiatan ini perlu dilakukan agar program-program perpustakaan perguruan tinggi mendapat dukungan dari pembuat keputusan, sehingga pencapaian tujuan dan sasaran dapat berjalan dengan lancar.

\section{Penutup}

Peningkatan kemampuan literasi informasi tidak sekadar menjadikan mahasiswa sebagai individu yang literat informasi untuk kepentingan penyelesaian tugas-tugas akademis belaka, melainkan juga untuk membekali mereka dengan pemahaman literasi informasi yang mendalam untuk kepentingan jenjang kariernya dan kepentingan bangsa. Pelaksanaan program tersebut merupakan tanggungjawab bersama dari perpustakaan, mahasiswa dan institusi penyelenggara pendidikan tinggi (perguruan tinggi/fakultas/jurusan). Karena itu langkah-langkah perpustakaan perguruan tinggi dalam melakukan pemeliharaan dan pembinaan hubungan baik, koordinasi, konsultasi serta advokasi dengan para pemangku kepentingan, memengaruhi keberhasilannya sebagai prime mover peningkatan kompetensi literasi informasi mahasiswa.

${ }^{52}$ Ahmad Rizani, “Optimalisasi Peran Advokasi Dalam Mempengaruhi Kebijakan Publik," 2015, 2, www.kompasiana.com. 


\section{DAFTAR PUSTAKA}

Adefolami, Dada. "What Is Competency," 2016. thenewsnigeria.com.ng.

Afifah. "Kemampuan Literasi Informasi Mahasiswa Dalam Menyelesaikan Tugas Penyusunan Skripsi (Studi Kasus Di Program Studi Pendidikan Agama Islam Fakultas Tarbiyah Dan Keguruan Universitas Islam Negeri Sultan Ampel Surabaya Angkatan 2011).” UIN Sunan Ampel Surabaya, 2015. digilib.uinsby.ac.id/6761.

Al Hamidy, Yusuf Dzul Ikram, and Heryanto. "Kemampuan Literasi Informasi Mahasiswa Pada Layanan American Corner Di UPT Perpustakaan IAIN Walisongo Semarang Menurut Association of College and Research Libraries," 2012. portalgaruda.org.

Anonim. "Prime Mover," 2017. https://en.wikipedia.org/wiki.

"Aristotle: The Prime Mover," 2015. www.scandalon.co.uk.

Astuti, Rini. "Menulis Karya Ilmiah." Staffsite (blog), n.d. http://riniastuti.staff.gunadarma.ac.id.

Baloch, Qadar Bakhsh, and Nasir Kareem. "Book Review: The Third Wave." Journal of Managerial Sciences; 137 I 2 (2007): 115-143.

Byrne, Alex, 2013. alex.byrne@uts.edu.au.

Cordel, Rosane Mary. "Information Literacy and Digital Literacy Competing or Complementary?, Northern Illinois University Communications in Information Literacy" Vol.7, no. 2 (2013). files.eric.ed.gov.

Dwiyanto, Agus. Reformasi Birokrasi Publik Di Indonesia. Yogyakarta: Pusat Studi Kependudukan dan Kebijakan Universitas Gadjah Mada, 2002.

. Transparansi Pelayanan Publik. Gadjah Mada University Press, 2005.

Gunasekera, Chamani. "Students Usage of an Academic Library: A User Survey Conducted at the Main Library University of Peradeniya" Vol. 14, no. 1 (2010). jula.sljol.info/article.

"Information Competency Defined," 2016. Information Competency Defined. 
Irawati, Indira. "Information Literacy Competency of Library and Information Science Students at the Faculty of Humanities University of Indonesia," 2014. www.slis.tsukuba.ac.jp.

K. Agyen-Gyasi. "User Education at the Kwame Nkrumah University of Science and Technology (KNUST) Library: Prospects and Challenges," 2008. digitalcommons.unl.edu.

Kurniawati, Rina. "Perpustakaan Perguruan Tinggi," 2014. rithateknodik.wordpress.com.

Kurniawati, Rita. "Perpustakaan Perguruan Tinggi." Sharing Education Berkarya Dan Berkarya Untuk Negeri (blog), 2014. https://rithateknodik.wordpress.com.

Lembaga Administrasi Negara. "Sistem Administrasi Negara Kesatuan Republik Indonesia," 2003. http://www/lan.go.id.

Marchionini, Gary, and Hermann Maurer. "The Roles of Digital Libraries in Teaching and Learning," 1995. https://ils.unc.edu.

Naibaho, Kalarensi. "Menciptakan Generasi Literat Melalui Perpustakaan." Visi Pustaka 9, no. 3 (2007): 1-8.

Nazir, Moh. Metode Penelitian. Jakarta: Ghalia Indonesia, 1999.

Niyamabrata. "Jenis-Jenis Metode Pendekatan Karya Tulis." Life Is About Choice (blog), 2013. ttps://konsen.wordpress.com.

Pinto, Maria, and Rosaura Fernandez-Pascual. "Information Literacy Competencies among Social Sciences Undergraduates: A Case Study Structural Equation Model," 2014. link.springer.com.

Poll, Roswitha. "Impact/Outcome Measures for Libraries," 2003. https://www.liberquarterly.eu.

Prasetiawan, Imam Budi. "Keberaksaraan Informasi (Information Literacy) Bagi SDM Pengelola Perpustakaan Di Era Keterbukaan Informasi," 2014. www.slis.tsukuba.ac.jp.

Rizani, Ahmad. "Optimalisasi Peran Advokasi Dalam Mempengaruhi Kebijakan Publik," 2015. www.kompasiana.com.

Schwab, K., X. Sala-i-Martin, and B. Brende. "The Global Competitiveness Report 2015-2016 (Vol. 5).” Google Scholar, 2015.

Soiferman, L. Karen. "Compare and Contrast Inductive and Deductive Research Approaches." Online Submission, 2010.

Sulistyo-Basuki. "Literasi Informasi Dan Literasi Digital," 2013. https://sulistyobasuki.wordpress.com. 
—. Pengantar Ilmu Perpustakaan. Jakarta: Gramedia, 1991.

Trivedi, Mayank. "Digital Libraries: Functionality, Usability, and Accessibility," 2003. www.webpages.uidaho.edu.

Usman, Husaini, and Purnomo Setiady Akbar. Metodologi penelitian sosial. Jakarta: Bumi Aksara, 2004.

Virkus, Sirje, and Silvi Metsar. "General Introduction to the Role of the Library for University Education," 2004. https://www.liberquarterly.eu. 
